Motrivivência Ano XXII, No 34, P. 40-60 Jun./2010

DOI:10.5007/2175-8042.2010n34p40

\title{
POLÍTICAS PÚBLICAS PARA \\ INCLUSÃO DIGITAL NAS ESCOLAS
}

Maria Helena Silveira Bonilla ${ }^{1}$

\begin{abstract}
Resumo Abstract
A partir do lançamento do Livro Verde do Programa Sociedade da Informação no Brasil, em 2000,

a discussão sobre inclusão digital toma o cenário nacional; no entanto, só começa a ser incorporada pelas escolas a partir de 2007, com a reformulação do Proinfo. Apesar do tema estar presente nos documentos, ainda está distante das

práticas pedagógicas. Este artigo discute essa problemática a partir da análise das políticas públicas para inclusão digital nas escolas brasileiras, apontando pontos críticos dessa articulação e indicando como

Since the presentation of the Green Book of the Society of Information Program in Brazil, in 2000, the discussion about digital inclusion takes national scene, however, starts being incorporated by the schools since 2007, with the Proinfo reformulation. Although the thematic is present in the documents, is far of pedagogic practices yet. This article discuss this problem since the analysis of public policies for digital inclusion in Brazilian schools, underling critical points of that articulation and indicating
\end{abstract}

1 Professora da FACED/UFBA, integrante do GEC (Grupo Educação e Comunicação). Contato: bonilla@ufba.br. 
possibilidade de superação da perspectiva instrumental da escola, a abertura para a vivência plena da cultura digital.

Palavras-Chave: políticas públicas, inclusão digital, escola pública as a possibility of getting over the instrumental perspective of school, the opening for the digital culture entire living.

Key-words: public policies, digital inclusion, public school
A partir do lançamento do Livro Verde do Programa Sociedade da Informação no Brasil, em 2000, o país incorpora em sua agenda política a universalização do acesso às tecnologias da informação e comunicação - TIC - e a promoção da "alfabetização digital" (BRASIL, 2000) da população, com o objetivo de assegurar que a economia brasileira tivesse condições de competir no mercado mundial. Nesse momento, ainda não estava posto na sociedade o termo "inclusão digital". Este surge, e se consolida, a partir dos debates em torno do Livro Verde e das análises que são elaboradas sobre o programa brasileiro.

Apesar do termo "inclusão" ser uma positivação de uma problemática social, a da exclusão, implicar o "entendimento do social a partir de uma concepção dual do dentro e do fora" (BONETI, 2005, p. 3), limitar a análise e bloquear a percepção da complexidade dos processos, carrega como potencialidade o fato de ser facilmente compreensível pela maioria da população, ter apelo midiático e ter provocado um movimento na sociedade brasileira em prol da universalização do acesso às TIC. Naquele momento inicial, o acesso, ou a infraestrutura de informações era tomado como o primeiro estágio rumo à Sociedade da Informação, tendo, claro, a informatização da economia como o segundo e fundamental estágio (BRASIL, 2000, p. 108). Ao tornar o crescimento econômico a principal preocupação política, a ponto de elevar, segundo Dahrendorf (1996, p.19), a economia à ideologia política, as questões sociais foram ignoradas ou então convertidas em valores econômicos. No entanto, os debates e a participação social nas iniciativas de universalização das TIC geraram uma outra dinâmica, mais em sintonia com as necessidades sociais da população brasileira.

Também, com a mudança de governo, em 2003, o Programa Sociedade da Informação no Brasil é deixado de lado, e as iniciativas governamentais para inclusão digital são incrementadas. Passam a 
compor as pautas de debates questões relacionadas à capacitação da população para o uso, oferta de serviços e conteúdos e as formas de utilização dessas tecnologias, questão esta, no nosso entender, fundamental para uma efetiva democratização das TIC, além, claro, das questões relacionadas à infraestrutura tecnológica. Estas questões são fundamentais, mas não suficientes para dar conta das necessidades sociais. Consideramos que é necessário ultrapassar a ideia de uso das TIC como ferramenta de capacitação para o mercado de trabalho, através de cursos técnicos para a população de baixa renda, ou então como meras ferramentas didáticas para continuar ensinando os mesmos conteúdos na escola, espaços onde normalmente é proibido o acesso a salas de bate-papo, jogos, comunidades virtuais e a uma outra variedade de sites. Enquanto isso acontece nos espaços de acesso público, os filhos das famílias com melhor poder aquisitivo estão explorando ampla e livremente os ambientes digitais, vivenciando a cultura, a interatividade, a produção colaborativa, a partir de seus computadores pessoais, em casa. Obviamente, promover uma iniciação da população, no uso das TIC, a chamada alfabetização digital, não deixa de ser uma ação social válida. No entanto, o que se discute é o quanto tais abordagens contribuem para que os sujeitos se articulem ativamente nas dinâmicas sociais contemporâneas, através das tecnologias, para gerar as transformações necessárias às suas demandas sociais, culturais e políticas. Também é fundamental discutir sobre o papel da escola nesse contexto.

\section{Inclusão digital e educação}

Em geral, observa-se que as questões culturais e educacionais estão presentes quando se discute inclusão digital. No entanto, quase sempre presentes de forma insuficiente. Na maioria das análises não está presente a perspectiva da produção de conteúdos, da colaboração, da autoria e co-autoria dos sujeitos no mundo digital, dimensão que efetivamente pode ser significativa educacionalmente para as comunidades, uma vez que somente se apropriando dessas possibilidades é que os sujeitos sociais poderão efetivamente participar das dinâmicas da web 2.0.

Observamos com frequência, e outras pesquisas também apontam nessa direção (OLIVEIRA, 2007; BUZATO, 2007), que a articulação entre os projetos de inclusão digital e a educação resume-se à realização de atividades escolares (pesquisas!) nos centros de acesso público. Isso é bastante significativo 
para os estudantes que não possuem conexão em casa, nem na escola. É uma oportunidade de interação com o contexto digital. No entanto, continua a perspectiva do consumo de informações, característica da web 1.0. Não está proposta, prevista, ou estimulada pelas políticas públicas uma articulação mais efetiva entre escola e demais espaços públicos de acesso. Para os gestores públicos, educação está em um plano de abordagem, e inclusão digital em outro, totalmente diferente, inclusive com responsabilização de secretarias e ministérios específicos, sem articulação entre eles.

$\mathrm{Na}$ verdade, as próprias escolas públicas enfrentam grandes dificuldades de ordem estrutural, pedagógica e tecnológica. Poucos alunos têm acesso às tecnologias em suas escolas e mais reduzido ainda é o número de professores que propõem atividades de aprendizagem articuladas diretamente com as TIC. Quando acontece, elas são utilizadas numa perspectiva instrumental, com cursos básicos em torno de algum software, ou para fazer uma pesquisa na internet, que em nada muda as dinâmicas já instituídas pela escola e largamente criticadas; também porque essas atividades, muitas vezes, são coordenadas pelos responsáveis pelos laboratórios e não pelos professores de sala de aula, ou então porque os professores não possuem formação para propor outras atividades, além das tradicionais pesquisas.

Mais recentemente, no Brasil, começa a aparecer nos projetos governamentais a perspectiva de promover inclusão digital nas escolas públicas. No entanto, ainda continua a percepção de que inclusão digital está numa dimensão e educação em outra. O Conselho de Altos Estudos e Avaliação Tecnológica da Câmara dos Deputados, ao avaliar a experiência Um Computador por Aluno - UCA, reconhece que

inclusão digital ora aparece como objetivo principal de programas de disseminação das TICs nas escolas, ora como um subproduto da fluência que as crianças ganham ao usar computador $\mathrm{e}$ Internet. A meta é a qualidade do processo de ensino-aprendizagem, sendo o letramento digital decorrência natural da utilização frequente dessas tecnologias. (CÂMARA DOS DEPUTADOS, 2008, p.52)

Como podemos perceber, a cultura digital não é considerada como parte integrante dos processos pedagógicos e das aprendizagens dos alunos. Continua a desarticulação entre escola e sociedade e a supervalorização da perspectiva conteudista da escola. 
De acordo com Warschauer (2006, p. 21), "para proporcionar o acesso significativo as novas tecnologias, o conteúdo, a língua, o letramento, a educação e as estruturas comunitárias e institucionais devem todos ser levados em consideração". Em vista disso, consideramos a escola como locus primeiro e natural dos processos de inclusão digital, aqui entendida como formação da cultura digital, uma vez que se constitui ela em espaço de inserção dos jovens na cultura de seu tempo - e o tempo contemporâneo está marcado pelos processos digitais. Como a escola deve ser espaço-tempo de crítica dos saberes, valores e práticas da sociedade em que está inserida, é da sua competência, hoje, oportunizar aos jovens a vivência plena e crítica das redes digitais. Logo, é responsabilidade do professor, profissional dessa instituição, a formação dos jovens para a vivência desses novos espaços de comunicação e produção. No entanto, um professor "excluído" digitalmente não terá a mínima condição de articulação e argumentação no mundo virtual, e, por conseguinte, suas práticas não contemplarão as dinâmicas do ciberespaço.

Portanto, para efetivamente transformar a escola num locus de inclusão digital, não basta o acesso às TIC (embora este seja fundamental, e necessário ser de qualidade!), precisamos investir na democratização do uso e na formação dos sujeitos sociais, em especial, dos professores. Algumas escolas, a partir de iniciativas da própria comunidade, estão abrindo seus laboratórios para uso da comunidade nos finais de semana, configurando-se em centros públicos de acesso às TIC, potencializando a inclusão digital de toda a comunidade escolar.

Ou seja, a escola começa a se constituir em espaço estratégico para promoção da inclusão digital. Essa perspectiva também está presente no projeto Um Computador por Aluno, que propõe, como uma de suas premissas, a posse do laptop pelo aluno, "a fim de garantir que ele (e sua família) possa levar o laptop para casa e se beneficiar de um maior tempo de USo" (CÂMARA DOS DEPUTADOS, 2008 , p. 44). No entanto, muito precisa ser investido para que escola se transforme num espaço de formação, dos professores, dos alunos e da comunidade escolar, para a vivência plena da cultura digital, como parte integrante de sua proposta pedagógica. Observamos que esta perspectiva parece estar ainda distante das atuais formulações políticas.

\section{As políticas públicas}

O que podemos perceber dentre os programas e ações de inclusão digital adotados pelo 
Governo Federal é que as ações do MEC ainda são incipientes. Até o momento, o principal programa que oportuniza o acesso das escolas à tecnologia digital é o Proinfo Programa Nacional de Informática na Educação, criado em abril de 1997, com o objetivo de melhorar a qualidade do processo de ensinoaprendizagem, possibilitar a criação de uma nova ecologia cognitiva nos ambientes escolares, propiciar uma educação voltada para o desenvolvimento científico e tecnológico e educar para uma cidadania global (MORAES, 1997). As estratégias para alcançar esses objetivos foram implantar laboratórios de informática nas escolas públicas de educação básica e capacitar os professores, gestores e outros agentes educacionais para a utilização pedagógica das tecnologias.

Apesar dos objetivos serem amplos, as estratégias sempre foram limitadas. Inclusive, sempre foi limitada a concepção que articula tecnologia e educação. Desde o início do processo no Brasil, as TIC são entendidas como ferramentas de apoio à educação. Essa perspectiva foi desenvolvida na década de 1980, a partir das discussões que marcaram o I e o II Seminário Nacional de Informática na Educação, promovidos pela SEI, MEC e CNPq, em 1981, em Brasília, e 1982, em Salvador, respectivamente. No I
Seminário, segundo Oliveira (1997, p. 29), tomou-se a posição de que o uso do computador deveria ser visto como ferramenta auxiliar do processo ensino-aprendizagem. No II Seminário, os pesquisadores recomendavam a

necessidade de que a presença de computadores na escola fosse encarada como um meio auxiliar no processo educacional, jamais deveria ser visto como um fim em si mesmo, e, como tal, deveria submeter-se aos fins da educação e não determinálos. Reforçava-se ainda a idéia de que o computador deveria auxiliar o desenvolvimento da inteligência do aluno, bem como desenvolver habilidades intelectuais específicas requeridas pelos diferentes conteúdos. (MORAES, 1993, p. 20)

Foi nessa perspectiva que o Proinfo se pautou, desde sua implantação, até porque um dos seus principais objetivos, o de conectar as escolas à internet, só começou a ser viabilizado a partir de 2008, com o Programa Banda Larga nas Escolas. Restava, então, formar os professores numa perspectiva instrumental, com cursos sobre como utilizar determinados softwares, visando animar as dinâmicas pedagógicas e torná-las mais atraentes, mas 
sem questionar o modelo instituído; ao contrário, reforçando-o. Essa forma de utilização da tecnologia, segundo Pretto (1996, p. 114), reduz as suas possibilidades e esvazia as TIC de suas características fundamentais, transformando-as em animadoras da velha educação.

Somente 10 anos após sua implantação, a SEED/MEC, em 2007, no contexto do Plano de Desenvolvimento da Educação $\mathrm{PDE}$, desenvolveu a reformulação do Proinfo, através do Decreto $n^{\circ}$ 6.300, de 12 de dezembro de 2007. O programa passou a chamar-se Programa Nacional de Tecnologia Educacional - Proinfo, e dividiu-se em dois: Proinfo Urbano e Proinfo Rural, com o objetivo de atender também as escolas situadas nas zonas rurais. Além da troca do nome e do alargamento da abrangência de cobertura, o programa adota, atualmente, a proposta de integração das mídias na educação e traz como objetivo "contribuir com a inclusão digital por meio da ampliação do acesso a computadores, da conexão à rede mundial de computadores $\mathrm{e}$ de outras tecnologias digitais, beneficiando a comunidade escolar e a população próxima às escolas" (BRASIL, 2007).

A primeira questão que se coloca é: por que trocar o nome do programa? Substituir "Informática" por "Tecnologia" parece ser uma boa opção, considerando que o programa passou a englobar as diferentes mídias, o que conferiu a ele uma maior abrangência. Agora, cabe questionar a troca dos termos "na Educação" por "Educacional". Quais os sentidos que estão postos nesses termos? Consideramos que o termo "na Educação" carrega um sentido mais amplo, inferindo que é possível, na educação, utilizarmos toda e qualquer tecnologia que esteja disponível na sociedade, de forma a proporcionar a vivência, na escola, de todas as possibilidades disponíveis nas redes digitais, contribuindo para a formação da cultura digital de todos. Já o termo "Educacional" carrega um sentido mais restrito, inferindo que existe uma tecnologia própria para a educação, uma vez que o "educacional" está posto como marca de um determinado tipo de tecnologia, ou seja, que só podemos utilizar na educação aquelas tecnologias que foram desenvolvidas especialmente para o ambiente escolar, o que, do nosso ponto de vista, constitui-se numa simplificação das suas potencialidades, e pouco contribui para os processos de inclusão digital dos alunos e professores. Justamente quando incorpora como objetivo o uso das mídias e a promoção da inclusão digital, o que exige a vivência plena do mundo digital, o programa fecha-se em torno de 
tecnologias específicas? Difícil compreender o motivo que levou à troca de nome do programa.

Frente a estes novos objetivos do Proinfo, e considerando a política nacional de inclusão digital, conectar as escolas à internet passou a ser fator estratégico do governo. Para tanto, em 04 de abril de 2008, através do Decreto Presidencial n. 6.424, foi lançado o Programa Banda Larga nas Escolas, com a participação das operadoras de telefonia e da Agência Nacional de Telecomunicações. Para conseguir a distribuição do serviço de banda larga nas escolas, o governo fez um acordo com as teles: elas deixaram de fornecer Postos de Serviços Telefônico (PST) em cada cidade brasileira, passando a distribuir seus backhauls ${ }^{2}$ em todos os municípios. Como no país, de acordo com Gindre (2008), mais de 2000 municípios não possuíam backhaul nessa época, ou seja, não contavam com cabeamento lógico e, em função disso, não podiam se conectar à banda larga, o programa visava, ao designar as teles para conectar 56 mil escolas da rede pública urbana do país até $2010^{3}$ e oferecer gratuitamente o acesso, atualizando periodicamente a velocidade até 2025 (período em vencem os atuais contratos de concessão das teles), disponibilizar o serviço para os demais setores da sociedade.

Com esse acordo, o governo abriu mão de usar sua própria infra-estrutura para fazer inclusão digital no país ${ }^{4}$, bem como dificultou o surgimento de experiências de redes comunitárias, utilizando tecnologia de redes sem fio, organizadas pela sociedade civil ou pelos poderes públicos locais, como já acontecia em Piraí no Rio de Janeiro, Tiradentes em Minas Gerais e Sud Menucci em São Paulo, as primeiras totalmente conectadas no país, e também no Pará e de Santa Catarina, estados que já se mobilizavam, investindo em redes próprias como estratégia de redução de custos e de maior autonomia

2 Backhaul, segundo a Wikipedia (http://pt.wikipedia.org/), é a "porção de uma rede hierárquica de telecomunicações responsável por fazer a ligação entre o núcleo da rede, ou backbone, e as subredes periféricas", ou seja, o backhaul das operadoras de telefonia, no Brasil, interliga o backbone de cada operadora às cidades.

3 Até meados de 2010, 47.204 escolas públicas urbanas de todo o Brasil contavam com acesso à internet, o que representa $72,75 \%$ dos estabelecimentos municipais, estaduais e federais localizados em zona urbana no país (ANATEL, 2010).

4 Essa perspectiva foi parcialmente revertida em 2010, no escopo do Programa Nacional de Banda Larga - PNBL, quando o governo brasileiro reativa a Telebrás para ser a gestora do processo e coordenar o uso da infraestrutura do governo no programa, de forma a atender as regiões onde as teles não chegam. 
(FONSECA, 2008, p. 18-20). Com o acordo, as teles

ganharam o direito de explorar sozinhas a rede que irão construir para chegarem até as escolas. Essa rede passará na porta de milhares de residências e obviamente as teles a usarão para vender seus serviços de banda larga. A proposta do governo não obriga a que as teles tenham que partilhar essa rede com os provedores locais (o tal unbundling). Com backhauls e redes de "última milha" para uso exclusivo, as teles acabaram de ganhar o monopólio da banda larga em todo o país. (GINDRE, 2008)

E após 2025, quem se responsabilizará pela conexão das escolas? Nada está previsto para a continuidade do oferecimento da conectividade. Ficamos dependentes da política do governo da época, e correndo o risco de termos uma descontinuidade nos projetos da maioria das escolas, uma vez que, historicamente, as mesmas não têm condições de pagar por esse serviço. Mas isso não será de causar estranheza, uma vez que a descontinuidade tem sido a marca dos programas e projetos de governo; a cada nova gestão, a maioria dos projetos em andamento são desconsiderados e uma nova leva emerge, de acordo com o modelo e as concepções do novo governo.

Também cabe analisar as condições que essas escolas terão, objetivamente, para elaborarem projetos pedagógicos com o uso das TIC. O programa Banda Larga nas Escolas faz parte da política do MEC para informatização das instituições de ensino e prevê a instalação de computadores nas escolas, a capacitação de professores e a oferta de conteúdos educacionais, através do Portal do Professor ${ }^{5}$ e do Banco Internacional de Objetos Educacionais ${ }^{6}$, "destinados a auxiliar os professores na oferta de conteúdos curriculares com recursos de multimídia" (MEC, 2008). Os computadores nas escolas e a capacitação dos professores são efetivados através do Proinfo, sendo que a capacitação ocorre em cursos a distância, acompanhados pela SEED/MEC.

E aqui voltamos mais uma vez à problemática da formação dos professores. Como formar professores que não possuem qualquer familiaridade com os ambientes digitais, em cursos a distância? Interagir com

5 http://portaldoprofessor.mec.gov.br/

6 http://objetoseducacionais2.mec.gov.br/ 
ambientes que apresentam uma lógica completamente diferenciada daquela que nos constituiu, não é tarefa simples. A presença de interlocutores é fundamental, pois são eles que dão o apoio necessário para superar os medos, as angústias, as inseguranças, ajudando os professores a superá-las, até mesmo segurando na mão para manusear o mouse (BONILLA; PRETTO, 2007, p. 83). Os Núcleos de Tecnologia Educacional - NTE - do Proinfo oferecem esse apoio, mas, para muitos professores ele é insuficiente, visto que o tempo para a familiarização é diferente para cada um de nós. Alguns se ambientam rapidamente, compreendem a lógica do digital e vão em frente, explorando, descobrindo e aprendendo. Outros não, necessitam de muito estímulo, apoio, estratégias intensivas e diferenciadas para provocar o desejo de interagir e conhecer os ambientes. Para estes, o processo pode ser bastante demorado, prologando-se por meses, ou até anos, conforme vivenciamos em nosso Programa de Formação de Professores em Exercício na Faced/UFBA ${ }^{7}$.

Os NTE também não conseguem atender a todos os professores das redes públicas do país. Então, muitas escolas estarão conectadas, com laboratórios, e limitando o trabalho à oferta dos famosos cursinhos de informática, ou às pesquisas na internet, práticas já difundidas e que não requerem envolvimento dos professores; basta um, responsável pelo laboratório da escola, e muitas vezes formado apenas em cursos técnicos. Ou seja, as escolas estarão conectadas "mas o sistema educacional, em última instância, pode permanecer o mesmo: hierárquico, vertical, centralizado de forma exagerada. Uma velha escola velha, com cara de moderna. Ou, quem sabe, pós-moderna!" (PRETTO, 2002, p.124).

Apesar de toda essa problemática, podemos considerar que estamos caminhando para a universalização do acesso à internet nas escolas urbanas do país, o que, por si só, apesar de insuficiente, significa a abertura da possibilidade de gerarmos um movimento de formação da cultura digital nesse contexto, quer entre os alunos, quer entre os professores. Agora, cabe perguntar: qual é a política pública para a conexão das escolas rurais, e para formação dos professores destas escolas?

Através da Portaria 431, de 23 de julho de 2009, do Ministério das Comunicações, foi instituído o

7 http://www2.faced.ufba.br/ 
Programa Nacional de Telecomunicações Rurais, com a finalidade de permitir à população localizada em áreas rurais o acesso a serviços, de interesse coletivo, de telefonia e de dados em banda larga (internet), sendo que a oferta desses serviços deverá ser simultânea, e privilegiando o uso de frequências do espectro radioelétrico na faixa de $450-470$ Mhz (BRASIL, 2009a), ou seja, busca-se, dessa forma, promover o incremento da oferta de aplicações em banda larga sem fio no país. A opção por essas faixas se deve ao fato de elas possibilitarem ótimas condições de propagação, sendo possível utilizar antenas com raio de cobertura de aproximadamente $50 \mathrm{~km}$, o que permite atender várias comunidades rurais com uma única estação rádio base. É, portanto, a mais apropriada para as zonas rurais e de baixa densidade.

A Portaria 431, em seu art. $2^{\circ}$, define o início do atendimento para 2010, devendo ser universalizado o serviço em cinco anos com a conexão de todas as escolas públicas rurais (BRASIL, 2009a). Um dos objetivos do programa é levar conexão banda larga para 80.000 escolas rurais até o final de 2014 (BRASIL, 2009b), o que não cobre toda a rede de escolas da área rural, a qual, de acordo com os dados levantados no Censo Escolar de 2005, é constituída por 96.557 estabelecimentos de ensino, o que representa cerca de $50 \%$ das escolas do País (207.234) (INEP/MEC, 2007).

A previsão é que a Anatel realize a licitação para a venda de licença para a prestação do serviço em 2010, mas ainda sem data definida, o que significa que o cronograma já está atrasado. Ou seja, como historicamente acontece no Brasil, as políticas, os programas, os projetos são instituídos, mas a sua implementação é lenta, fazendo com que se gere a expectativa da oferta dos serviços, e ao mesmo tempo a percepção da ineficiência das políticas públicas. A grande expectativa volta-se então para o Programa Nacional de Banda Larga - PNBL, instituído em 2 de maio de 2010, através do Decreto $n^{\circ} 7175$, que se encontra em fase de implantação. O Decreto não prevê prazo para a universalização dos serviços, mas segundo o Plano Nacional de Banda Larga, a meta é atingir 90 milhões de acessos banda larga em 2014, atendendo 100\% dos órgãos de Governo, incluindo escolas públicas ainda não atendidas (mais de 70.000 rurais) (BRASIL, 2009b, p. 14).

Enquanto isso, apenas algumas escolas rurais são atendidas com conexão via satélite, pelo Programa GESAC, visto este não ter capacidade para atender toda a demanda. No final de 2009, o GE- 
SAC contava com 11.000 pontos de presença em 4.750 municípios brasileiros, atendendo escolas e órgãos públicos, sindicatos, aldeias indígenas, comunidades quilombolas e ribeirinhas, zonas rurais, periferias urbanas, telecentros comunitários e pontos remotos de fronteira, sedes de organizações não-governamentais e/ ou onde já existam outros projetos de inclusão digital do Governo Federal (BRASIL, 2010).

Como pode-se perceber, a universalização do acesso internet nas escolas rurais ainda está longe de se efetivar. Enquanto isso, através do Proinfo Rural, laboratórios com solução multiterminal (5 terminais de acesso com 1 CPU) estão sendo distribuídos às escolas com mais de 30 alunos, e que possuam energia elétrica. Até o final de 2009, cerca de 19.000 escolas haviam recebido os equipamentos, o que corresponde a $20 \%$ das escolas rurais brasileiras, e significa um longo caminho até a universalização do acesso aos equipamentos nessas escolas, inclusive porque não depende apenas da disponibilização dos equipamentos. Também é necessário investir em infraestrutura básica - energia elétrica e salas adequadas -, o que muitas escolas não possuem.

A formação dos professores dessas escolas também está sujeita aos mesmos problemas enfrentados pelos professores das escolas urbanas. Compete aos NTE formar os professores das escolas que recebem os laboratórios do Proinfo Rural, mas como a maioria dos cursos do NTE se efetivam na modalidade a distância, e a maioria dos professores e das escolas não contam com conexão internet, fica difícil a esses professores participarem das formações. Ou seja, as políticas públicas precisam estar integradas (políticas para conexão, infraestrutura, equipamentos, formação dos professores), para que efetivamente possamos falar em inclusão digital nas escolas, especialmente nas escolas rurais, considerando as carências enfrentadas por estas no Brasil. O que presenciamos, é um conjunto de programas e projetos, iniciativas válidas, mas que no processo de implementação não conseguem fortalecer-se mutuamente e atender a todas as demandas das escolas.

Um outro projeto que faz parte desse conjunto, e que visa potencializar a inclusão digital dos professores que estão ativos, tanto nas redes públicas, quanto na rede privada de educação básica, profissional e superior, é o Projeto Computador Portátil para Professores, instituído em 04 de julho de 2008, através do Decreto Presidencial $n$. 6504, no âmbito do Programa de Inclusão Digital, com a participação da Empresa Brasileira de Correios e 
Telégrafos - ECT. O previsto é que o projeto possibilite a cada professor a compra de um notebook pelo valor de até $\mathrm{R} \$ 1.400,00$. O entendimento é que os notebooks podem "auxiliar na formação intelectual e pedagógica dos professores, a partir da interação com as novas tecnologias da informação e comunicação" bem como "propiciar um ambiente favorável à inovação na área de educação, paralelamente ao desenvolvimento de futuras tecnologias na área pedagógica e social, contribuindo assim para a melhoria da qualidade do ensino público brasileiro" (BRASIL, 2008).

Consideramos que o acesso dos professores aos computadores é fundamental, até porque a maioria deles não dispõe dessa tecnologia em suas casas ou escolas. No entanto, sem uma política forte de formação para o seu uso, como poderá o professor, sozinho, formarse intelectual e pedagogicamente, inovar e desenvolver tecnologia? Atribuir essa função ao professor, individualmente tem como base a concepção de que os sujeitos aprendem espontaneamente a interagir com os ambientes digitais, online e offline. Essas aprendizagens acontecem efetivamente, mas são mais comuns entre os jovens, desejosos de viver e experimentar a não-linearidade da cultura digital. Entre os adultos, e mais ainda entre os professores, a falta de conhecimento e domínio do ambiente e da lógica digital provoca estranhamento e medo pelo desconhecido, pois, ao entrar em contato com essa nova realidade, o professor fica diante de fatos que eram inexistentes em sua cultura de origem e, na maioria das vezes, foi inexistente em sua formação inicial.

Bonilla e Pretto (2007), ao analisarem a relação que os professores, participantes do Programa de Formação Continuada de Professores para o município de Irecê - BA, desenvolvido pela Faced/UFBA, estabelecem com as TIC, reconhecem a importância do acesso, mas consideram que este não é condição suficiente para a construção da cultura digital e a produção de conhecimentos requeridos pelas dinâmicas de um curso de formação. Para viabilizar tais dinâmicas, é necessário a abertura para a liberdade de experimentar diversas possibilidades oferecidas pelas TIC, compartilhando descobertas e aprendizados, de forma a quebrar a máxima "cada um por si" e instituir uma organização colaborativa que propicie a multiplicação de ideias e a constituição de uma nova cultura, a cibercultura.

O Projeto Computador Portátil para Professores foi criado em julho de 2008, mas sua implementação foi iniciada apenas no 
final de agosto de 2009, abrangendo inicialmente 64 municípios, numa fase de testes. A segunda fase iniciou em meados de outubro de 2009, atendendo todos os municípios brasileiros. No site dos Correios, em setembro de 2010, apenas uma opção de computador estava disponível ${ }^{8}$ para venda. Ou seja, mais um projeto com implementação lenta, cheio de limitações e de retrocessos, uma vez que não são oferecidas as condições básicas (diversidade de oferta e/ou articulação entre os diversos setores envolvidos) para que os mesmos possam ser colocados à disposição da população.

Outro projeto vinculado ao MEC é o UCA (Um Computador por Aluno) que vem sendo desenvolvido desde $2007^{9}$ e "visa criar e socializar novas formas de utilização das tecnologias digitais nas escolas públicas brasileiras, para ampliar o processo de inclusão digital escolar e promover o uso pedagógico das tecnologias de informação e comunicação" (UCA, 2009 , p. 1). Este é outro projeto com implementação lenta, devido a problemas nos processos de aquisição dos computadores. No final de 2007 o governo abriu licitação para aquisição de 150 mil laptops para a fase Il do projeto, mas no início de 2008 cancelou o pregão, em virtude de os preços dos laptops estarem acima do projetado. No final de 2008, nova licitação foi aberta e, uma vez mais, o andamento do processo foi paralisado por ordem do Tribunal de Contas da União, em virtude de denúncias de irregularidades no edital.

Em meio a essas idas e vindas, em 05 de julho de 2008 , o jornal Folha de São Paulo divulgou uma nota informando que o Presidente Lula havia desistido de comprar os laptops por considerar que o projeto ficou caro demais e que teria menos eficiência do que instalar laboratórios de informática nas 55 mil escolas públicas do país. No entanto, o Conselho de Altos Estudos e Avaliação Tecnológica da Câmara dos Deputados, ao avaliar a experiência, reconhece que a montagem de laboratórios de informática, a exemplo do Proinfo, restringe o uso dos alunos a uma carga horária reduzida, e a uma grade de disciplinas, mantendo as mesmas dinâmicas do sistema tradicional de ensino, não adequado aos espaços-tempos necessários para a construção do

8 O modelo disponível no site dos Correios, em setembro de 2010, era o CCE WIN ILP 232 - Notebook 14.1" Intel Pentium Dual Core T4.200 2,0Ghz 2GB HD320GB, no valor de R\$1.199,00.

9 De 2007 a 2009 o programa encontrava-se em sua fase pré-piloto, em desenvolvimento em cinco escolas brasileiras: Porto Alegre, São Paulo, Brasília, Palmas e Piraí-RJ. 
conhecimento na contemporaneidade. Essa metodologia também não propicia a vivência plena da cultura digital, componente fundamental dos processos de inclusão digital.

A imersão tecnológica da escola propicia o desenvolvimento de uma "cultura digital", na qual os alunos têm suas possibilidades de aprendizagem ampliadas pela interação com uma multiplicidade de linguagens ao mesmo tempo em que se potencializa a inclusão digital de toda a comunidade escolar. (CÂMARA DOS DEPUTADOS, 2008, p. 16)

Apesar dessa potencialidade estar presente no projeto UCA, uma vez que os alunos estarão em contato mais intenso e livre com os laptops, podendo se comunicar, produzir vídeos, explorar os mais diversos ambientes online, não estava explicitada nos primeiros documentos essa perspectiva de inclusão digital. Tais documentos, quando referiamse à inclusão digital, reportavam-se à possibilidade de uso pela família de cada aluno e também ao acesso a serviços do governo eletrônico disponíveis online. O foco do projeto era o potencial pedagógico dos laptops na sala de aula. E nem isso estava claramente definido. $\mathrm{O}$ que é entendido como pedagógico? Essa dimensão está limitada aos conteú- dos curriculares? É a perspectiva de uso da tecnologia como ferramenta de ensino? Qual a relação entre a dimensão pedagógica e a inclusão digital? Apesar de essas questões não estarem em discussão, nem haver clareza sobre a imbricação entre elas, a avaliação do Conselho de Altos Estudos e Avaliação Tecnológica da Câmara dos Deputados já indicava que "nos moldes atuais, a inclusão digital oferecida pelos programas pré-piloto é um tanto quanto limitada, ainda que mais efetiva do que a ofertada pelos laboratórios de informática" (CÂMARA DOS DEPUTADOS, 2008, p. 161). Isso porque, nessa fase pré-piloto, mesmo levando os laptops para casa, os alunos não dispunham de conexão internet. Também, quase todas as escolas estabeleceram políticas de restrição de conteúdos, bloqueando o acesso a determinados sites. O documento da Câmara dos Deputados anuncia que alguns docentes e gestores revelaram que, no primeiro mês, foi preciso ser tolerante e permitir a exploração de aplicativos, orkut, games e sítios de interesse da garotada, mas que, após essa fase inicial de exploração, os bloqueios foram impostos. Ou seja, exploração desses ambientes, para formação da cultura digital, é confundida com "tolerância", e considerada como algo "menor", sem valor educacional e que, portanto, deve ser excluída da escola. 
Apesar de todas essas limitações na implementação do projeto e no trato com o tema da inclusão digital em sua fase prépiloto, durante todo o ano de 2009 o projeto prosseguiu, com a tramitação do pregão para a compra dos equipamentos, a seleção das escolas que comporiam a próxima fase (piloto) e a realização da avaliação das cinco experiências, com cada instituição elaborando relatórios sobre a escola (descrição e contexto), a infra-estrutura e as questões técnicas, os problemas e as soluções relacionados à gestão da escola, e ainda sobre as experiências educativas relacionadas ao uso dos equipamentos. Então, em janeiro de 2010 foi divulgado que o consórcio CCE/DIGIBRAS/ METASYS foi vencedor do pregão para o fornecimento de 150.000 laptops educacionais, a um preço unitário de $R \$ 550,00$, para as 300 escolas públicas selecionadas nos estados e municípios para integrar a próxima etapa do projeto. A partir de então o mesmo ganha força, com a organização das equipes de formação e pesquisa e o envolvimento das IES na operacionalização da fase piloto do projeto - formação dos professores das 300 escolas e acompanhamento do processo. É nesta fase que se encontra o projeto neste momento. Os laptops chegaram às escolas selecionadas e os professores começaram o processo de formação. Como os processos de inclusão digital, ou seja, de formação da cultura digital serão desencadeados a partir daqui depende dos encaminhamentos dados pelas equipes das IES durante a formação, mas também das diretrizes postas nos documentos do projeto.

Os documentos elaborados para esta nova fase apresentam um alargamento na perspectiva de inclusão digital e de uso dos computadores nas escolas. O livreto Formação Brasil (UCA, 2009) continua destacando a importância do uso pedagógico dos laptops, mas também destaca a necessidade de criação de uma cultura de redes cooperativas, de utilização das ferramentas interativas da web 2.0, do desenvolvimento de processos cooperativos e solidários, de um uso mais intenso dos processos comunicacionais, da movimentação da escola no sentido de constituirse uma organização aprendente, que se desenvolve e reestrutura a partir das práticas horizontalizadas que vão sendo propostas. São justamente esses objetivos que podem viabilizar a imersão da escola (alunos, professores e comunidade) na cultura digital, desde que efetivamente todos tenham a liberdade de explorar a multiplicidade de linguagens e ambientes online. 
Caso contrário, teremos mais uma vez a redução dos laptops a uma mera ferramenta, a ser enquadrada na rigidez e na chatice da escola, bem como a manutenção do modelo comunicacional de transmissão de informações. Neste caso, a tecnologia continuará a ser tomada como um recurso a mais, que serve apenas para complementar ou animar uma prática já instituída e não para transformar as formas de pensar e produzir conhecimento. Alguns pesquisadores apontam a limitação desta perspectiva. Nelson Pretto, em entrevista à Revista ARede, afirma que

apropriar-se dessas tecnologias como uma mera ferramenta, do meu ponto de vista, é jogar dinheiro fora. Colocar computador, recursos multimídia e não sei mais o quê para a mesma educação tradicional, de consumo de informações, é um equívoco. Ou nós trazemos essas tecnologias com a perspectiva de modificar a forma de como se ensina e de como se apreende - e isso significa, fundamentalmente, entender a interatividade e a possibilidade da interatividade como sendo o grande elemento modificador dessas relações -, ou vamos continuar formando cidadãos que são meros consumidores de informações. O que nós precisamos- e essa é a chave do que eu defendo - é formar cidadãos produtores de cultura e de conhecimento. $E$, para isso, a tecnologia é fascinante. (PRETTO apud DIAS, 2006).

Bonilla e Picanço (2005, p. 224-225) afirmam que para ultrapassar essa perspectiva instrumental, as TIC devem ser tomadas como elementos estruturantes das ações, mais especificamente, que a REDE deve ser incorporada às práticas presenciais de forma paralela, integrada e integrante com o conjunto das demais atividades, de forma a favorecer a vivência da interatividade, da colaboração, da auto-organização, da conectividade plena e efetiva com outros nós que vão surgindo ao longo do processo e não apenas com aqueles delineados a priori. Desta forma, o imprevisto, o diverso, o múltiplo integra o processo educativo, que se transforma em um processo dinâmico, em constante movimento. As subjetividades, as culturas, os conhecimentos entrelaçam-se nas vivências desses novos espaçostempos, transformando os sujeitos e as sociedades.

Tais perspectivas estão em sintonia com os estudos de Castoriadis (1987), quando afirma que 
um objeto técnico não é um "instrumento" puro; deve ser tomado em uma rede de significações, que depende da cultura e cuja eficácia produtiva é só um momento desse processo. Dessa forma,

objeto não é nada como objeto técnico fora do conjunto técnico [...] a que pertence. [..] [Também] não é nada fora das desteridades corporais e mentais (que não são absolutamente evidentes nem automaticamente induzidas pela simples existência do objeto) que condicionam sua utilização; a ferramenta como tal, [...] 'só é o testemunho da exteriorização de um gesto eficaz'. Conjunto técnico e desteridades podem tanto induzir à invenção, ou ao empréstimo de um objeto, quanto modificar, às vezes 'regressivamente', as suas modalidades de uso [...] ou condicionar o seu produto. Enfim esse objeto é ele próprio um produto; sua gênese contribui portanto à totalidade da existência social da coletividade que o originou: não só suas 'aptidões mentais', mas sua organização do mundo e o viés específico que o caracteriza. [...] O próprio conjunto técnico é privado de sentido, [técnico ou outro], se o separarmos do conjunto econômico e social. (CASTORIADIS, 1987, p.251)
É o que podemos vivenciar, contemporaneamente, com as redes digitais, especialmente na geração da Web 2.0, que valoriza as práticas colaborativas, a comunicação, a resolução de problemas, a autoria, em comunidades virtuais, que se articulam em torno de objetivos comuns, independentemente do local de origem de cada um de seus membros. Essas comunidades criam um movimento horizontal que fortalece aqueles que se encontram às margens dos centros de poder de decisão da sociedade, ou as "bordas da rede" (PRIMO, 2008, p. 64), transformando as formas de ser, conhecer, comunicar e produzir em sociedade.

Promover a inclusão digital é, na nossa percepção, oportunizar que cada sujeito social possa, efetivamente, participar desse movimento, não sujeitando-se às práticas que o condicionam a mero consumidor, seja de informações, seja de bens, seja de cultura. O papel da educação é favorecer a "luta pela prevalência da colaboração e do compartilhamento sobre a competição e o aprisionamento do conhecimento" (BRANT, 2008, p. 73), ser um espaço de crítica e ressignificação de todos os processos sociais, de forma a tornar-se um fator de liberdade do conhecimento, dos sujeitos, da sociedade. Para tanto, as políticas públicas de inclusão 
digital na escola necessitam estar articuladas, não só na origem, mas, especialmente, na implementação, bem como envolver toda o processo que leva à formação da cultura digital da comunidade escolar, urbana e rural, desde a conexão à internet, passando pela infraestrutura, pela disponibilidade dos esquipamentos, pela formação dos professores, até a reorganização dos espaços-tempos escolares. O desafio está posto!

\section{Referências}

ANATEL. Relação de Escolas Públicas Urbanas Conectadas. $04 \mathrm{de}$ junho de 2010. Disponível em <http://sistemas.anatel.gov.br/ sici/Relatorios/BandaLarga/tela. asp > Acesso em: 30 set 2010.

BONETI, Lindomar W. Educação Inclusiva ou Acesso à Educação. In: 28a. RA da Associação Nacional de Pós-Graduação e Pesquisa em Educação - ANPED, 2005, Caxambu - MG. Rio de Janeiro: Edição da ANPED, 2005. v. 01 (Anais).

BONILLA, Maria Helena Silveira; PICANÇO, Alessandra de Assis. Construindo novas educações. In: PRETTO, Nelson De Luca. Tecnologia e novas educações. Salvador: EDUFBA, 2005, p. 216- 230.
BONILLA, Maria Helena; PRETTO, Nelson De Luca. Formação de Professores: as TIC estruturando dinâmicas curriculares horizontais. In: ARAÚJO, Bohumila; FREITAS, Katia S. (coords.). Educação a Distância no contexto brasileiro: experiências em formação inicial e formação continuada. Salvador: ISP/ UFBA, 2007. p.73-92.

BRANT, João.O lugar da educação no confronto entre colaboração e competição. In.: PRETTO, Nelson De Luca; SILVEIRA, Sergio Amadeu (Orgs). Além da redes de colaboração: internet, diversidade cultural e tecnologias do poder. Salvador: EDUFBA, 2008. p. 69-74.

BRASIL. Sociedade da Informação no Brasil. Livro Verde. Brasília: Ministério da Ciência e Tecnologia, 2000.

BRASIL. PRESIDÊNCIA DA REPÚBLICA. Decreto $\mathrm{n}^{\circ} \mathbf{6 . 3 0 0}$, de 12 de Dezembro de 2007. Dipõe sobre o Programa Nacional de Tecnologia Educacional - Prolnfo. Decreto on-line. Disponível em : < http://www. planalto.gov.br/ccivil_03/ Ato2007-2010/2007/Decreto/ D6300.htm >. Acesso em: 17 de abril de 2009. 
BRASIL. Computador Portátil para Professores. 2008. Disponível em: <http://www. computadorparaprofessores.gov. br $>$. Acesso em: 12 de abril de 2009.

BRASIL. Ministério das Comunicações. Portaria $\mathrm{n}^{\circ}$ 431, de 23 de julho de 2009. Institui o Programa Nacional de Tecomunicações Rurais. Diário Oficial da União. Seção 1. Ano CXLVI - no 140, Brasília - DF, sexta-feira, 24 de julho de 2009a, p. 58.

BRASIL. Ministério das Comunicação. Um plano nacional para banda larga: o Brasil em alta velocidade. Brasília, 2009b. Disponível em < http://www.mc.gov.br/ wp-content/uploads/2009/11/obrasil-em-alta-velocidade1.pdf $>$. Acesso em: 08 abr 2010.

BRASIL. Cartilha GESAC. $2^{a}$ ed. Brasília: Ministério das Comunicações, 2010. Disponível em < http://www.gesac.gov. br/images/pdf/cartilha gesac formato_a6_-_09_04_2010.pdf $>$. Acesso em 02 de junho de 2010.

BUZATO, Marcelo. Entre a Fronteira e a Periferia: linguagem e letramento na inclusão digital. Tese (Doutorado em Lingüística Aplicada) - Instituto de Estudos da Linguagem, Universidade Estadual de Campinas, Campinas, 2007.

CÂMARA DOS DEPUTADOS.
Conselho de Altos Estudos e Avaliação Tecnológica. Um

Computador por aluno: a experiência brasileira. Brasília: Câmara dos Deputados, Série Avaliação de Políticas Públicas, Brasília/DF, n.1, 2008.

CASTORIADIS, Cornelius. As encruzilhadas do labirinto. Rio de Janeiro: Paz e Terra, v.1, 1987.

DAHRENDORF, Ralf. A quadratura do círculo: bem-estar económico, coesão social, liberdade política. Lisboa : Edições 70, 1996.

DIAS, Lia Ribeiro. Geração alt-tab deleta fronteiras na educação. Revista Arede: tecnologia para a inclusão social. São Paulo, ed. 16, julho/2006. Disponível em: $<$ http://www.arede.inf.br/index. php?option $=$ com_content\&task $=$ view\&id $=634 \&$ Itemid $=99>$. Acesso em: 14 de abril de 2009.

FONSECA, Fátima. Estados criam redes próprias de telecom. Revista ARede: tecnologia para a inclusão social, São Paulo, ano 4, n. 37, jun 2008, p.18-20.

GINDRE, Gustavo. Governo troca política de inclusão digital ampla por banda larga nas escolas. Observatório do Direito à Comunicação, 2008. Disponível em:< http://www. direitoacomunicacao.org.br/ novo/content.php?option $=$ com ontent\&task $=$ view\&id $=3090>$. Acesso em: 12 de abril de 2009. 
INEP/MEC. Panorama de Educação do Campo. 2007. Disponível em < http://www.publicacoes. in e p.gov.br/d e tal hes. asp?pub $=4181 \#>$. Acesso em 02/09/2009.

MEC. Mais escolas terão internet banda larga. 2008 . Disponível em: < http://portal.mec.gov.br/ index.php?option $=$ com conte $\mathrm{nt} \& \mathrm{view}=$ article \&id $=11 \overline{7} 12 \& \mathrm{c}$ atid $=210>$. Acesso em: $12 \mathrm{de}$ abril de 2009.

MORAES, Maria Candida. Informática educativa no Brasil: um pouco de história... In: Em Aberto. Brasília, ano 12, n. 57, jan./mar. 1993. p. 17-26.

MORAES, Maria Candida. Subsídios para fundamentação do Programa Nacional de Informática na Educação (Proinfo). Brasília, SEED/MEC, jan/1997. Disponível em:<http://www. dominiopublico.gov.br/pesquisa/ DetalheObraForm.do?select action $=\&$ co obra $=22150>$. Acesso em: $1 \overline{4}$ de abril de 2009.

OLIVEIRA, Paulo Cezar. Resignificações da Inclusão Digital: Interfaces Políticas e Perspectivas Socioculturais nos Infocentros do Programa Identidade Digital. Dissertação (Mestrado em Educação) - Faculdade de Educação, Universidade Federal da Bahia, Salvador, 2007.
OLIVEIRA, Ramon de. Informática Educativa. Campinas, SP : Papirus, 1997.

PRETTO, Nelson De Luca. Uma escola com/sem futuro. Coleção magistério: formação e trabalho pedagógico Campinas: Papirus, 1996.

PRETTO, Nelson. Formação de professores exige rede. Revista Brasileira de Educação, n. 20, maio/ago. 2002. p. 121-131.

PRIMO, Alex. Fases do desenvolvimento tecnológico e suas implicações nas formas de ser, conhecer, comunicar e produzir em sociedade. In.: PRETTO, Nelson De Luca; SILVEIRA, Sergio Amadeu (Orgs). Além da redes de colaboração: internet, diversidade cultural e tecnologias do poder. Salvador:EDUFBA, 2008. p. 51-68.

UCA. Um computador por aluno. Formação Brasil: projeto, planejamento das ações/cursos. Brasília: SEEC/MEC, 2009.

WARSCHAUER, Mark. Tecnologia e inclusão social: a exclusão digital em debate. Trad: Carlos Szlak. São Paulo: Editora Senac, 2006.

Recebido: agosto/2010. Aprovado: outubro/2010. 